\title{
Chapter 5 \\ An Expressivist Disability Critique of the Expansion of Prenatal Genomics
}

\author{
Chris Kaposy
}

\begin{abstract}
Prenatal genomics appears to be on an expansive trajectory toward universally-available, routine, whole-genome prenatal sequencing. But for people living with disabilities, this expansion of prenatal genomics may not be a welcome development. This chapter explores some of the objections arising from the community of people with disabilities, and articulates a defense of one particular form of objection: the claim that the expansion of prenatal genomics expresses negative messages about people with disabilities.
\end{abstract}

\subsection{Introduction}

An increasing variety of screening and diagnostic products are being offered to pregnant women as a result of advances in prenatal genomics. These advances have improved the accuracy of prenatal testing modalities, expanded the variety of indications for which testing is available, and made testing more patient-friendly. But for people living with disabilities, this expansion of prenatal genomics may not be a welcome development. Here I explore some of the objections arising from the community of people with disabilities, and articulate a defense of one particular form of objection-the claim that the expansion of prenatal genomics expresses negative messages about people with disabilities.

These disability-related critiques focus on two ways in which prenatal genomics has expanded. First, in less than a decade, noninvasive prenatal tests (NIPT) have been made available to pregnant women, and the number of genetic differences for which these tests can be used has steadily increased. Originally developed to test for Down syndrome, some new generation noninvasive tests also report on the presence of: trisomies 13 and 18, the sex of the fetus, sex chromosome differences, extra genetic material at the sub-chromosomal level, and genetic material that is missing at this level (Sequenom 2017). The "MaterniT GENOME" test marketed by Sequenom

C. Kaposy $(\otimes)$

Memorial University of Newfoundland, Newfoundland, Canada

e-mail: christopher.kaposy@med.mun.ca 
Laboratories is an example (Sequenom 2017). The expansion of noninvasive tests appears to be on a trajectory towards prenatal whole-genome sequencing, a testing modality that would make it possible for prospective parents to have information about a fetus's complete genome (Munthe 2015).

A second aspect of the expansion of prenatal genomics is the possibility that NIPT and future technologies such as prenatal whole-genome sequencing will lead to more utilization of prenatal testing. NIPT for Down syndrome appears to be more accurate than previous screening tests, which could lead to a decrease in the number of pregnant women who are exposed to invasive diagnostic testing. Invasive tests such as amniocentesis and chorionic villus sampling carry a small risk of miscarriage. Because of the improvements of NIPT over previous screening tests, it is likely that more people will undergo prenatal testing. The use of NIPT is also likely to expand as coverage increases under public and private insurance plans, contributing to the perception that it is a routine prenatal intervention. The expanded use of NIPT could then lead to an increase in terminations of pregnancies because of fetal diagnoses of disability (Kaposy 2013, 2018; Nuffield Council on Bioethics 2017).

In addition to NIPT and whole-genome sequencing, the arguments presented in this chapter will touch on other technologies, such as preimplantation genetic diagnosis (PGD), in which the genetic material of embryos created through in vitro fertilization (IVF) are analyzed prior to implantation. Another relevant genomic technology is chromosomal microarray (CMA) which enables a high-resolution analysis of chromosomes for the purposes of detecting small additions and subtractions of chromosomal material (Nuffield Council on Bioethics 2017). CMA is often used after the extraction of samples through an invasive procedure such as amniocentesis.

Advances in genomics have also given us the gene-editing technology CRISPRCas9, which enables genetic alterations of one's offspring that are inherited and passed on to future descendants. Unlike NIPT, PGD, and CMA, CRISPR-Cas9 is currently considered a research tool and is not in clinical use. However the formidable power of this technology has engendered public debate about whether it ought to be used to reverse heritable genetic conditions, including genetic differences associated with disabilities (Baylis 2017b; International Summit on Human Gene Editing 2015).

For the most part, this chapter focuses on disability critiques directed at NIPT. I analyze the expansion of prenatal genomics in the form of NIPT as a social phenomenon that includes networks of actors, such as clinicians, the biotech industry, policy-makers who make funding decisions and who contribute to the development of practice guidelines, as well as prospective parents who are the consumers of these technological products. The social phenomenon of prenatal testing, which includes many actions and events that have contributed to the expansion of prenatal genomics, can be interpreted as conveying negative messages about people with disabilities, or so I will argue. When people with disabilities for which prenatal tests have been developed witness the social phenomenon of prenatal testing, they are justified in their interpretation that this networked series of actions and events expresses negative messages about them. In particular, the negative message that is eminently derivable from this social phenomenon is that people with disabilities ought not to have been born. 
As Bjørn Hofmann has noted, this "expressivist objection" to prenatal testing is "somewhat unfashionable in the ethics literature" these days (Hofmann 2017, 1). But Hofmann himself, along with others, have begun to give expressivist arguments new attention (also Gyngell and Douglas 2016). Though my position is importantly different from Hofmann's, this chapter is meant to contribute to the re-invigoration of expressivist objections to prenatal testing, as part of the expansion of prenatal genomics.

To begin, I canvass some disability-based objections to the expansion of prenatal genomics that result from concerns about the consequences of the widespread use of these technologies. In particular I focus on the potential for prenatal testing technologies to contribute to the pathologization of disabilities, and the consequences of pathologization. From there I develop my argument in support of the expressivist objection to the expansion of prenatal genomic technologies. According to this argument, the social phenomenon of prenatal testing has unfolded against a backdrop of the medicalization of pregnancy and of disabilities, and this context of medicalization enables the social phenomenon to convey a discernable negative message about disabilities.

\subsection{Concerns About Consequences}

One main line of objection to the expansion of prenatal genomics derives from fears that this expansion will result in a reduction of people with the conditions for which there is testing - for example, conditions like Down syndrome, or sexchromosome aneuploidies. The Down syndrome advocacy group "Don't Screen Us Out" gives voice to such an objection. The group describes the projected decrease in the population of people with Down syndrome in the UK due to the use of NIPT as “informal eugenics" (Don't Screen Us Out 2017). To those who share this concern, it might be offensive in itself that people like themselves, or people like their children, family members, or friends, are being systematically eliminated from the human population.

Decreasing populations of people with particular disabilities might have negative effects on those who live with such disabilities. For instance, some have voiced concern that decreased populations will result in a diminution of research funding devoted to such conditions. The Nuffield Council on Bioethics outlines how low prevalence of a condition or disease in a population corresponds to a low priority in research funding in several countries (Nuffield Council on Bioethics 2017, 57). A lack of research funding can translate into a lack of treatments or therapies for a disability, which can negatively affect health and well-being. Dr. Ségolène Aymé who chairs the rare disease Topic Advisory Group at the World Health Organization points out that for such diseases, "knowledge is scarce, the experts are few, the healthcare system is not organized for these patients, and the market is too small to be attractive when it comes to developing new therapies" (Aymé 2016). 
Similarly, some fear that a reduction in the number of people with genetic conditions will result in a reduction in public provision for health and social support. Mary Casagrande, a Canadian mother of a child with Down syndrome, expresses her fear that "if the number of people with Down syndrome is dramatically reduced ... the supports are not going to be there for people who have an intellectual disability because the need won't be there as much" (Grant 2018). Since funding for specific health care needs typical of people with cognitive disabilities are often tied to the prevalence of such disabilities in the population, appropriate funding might not be directed toward people with rarer conditions.

Some have expressed worry that the expansion of prenatal genomics and subsequent reduction in the populations of people with disabilities will translate into more bias against people with such disabilities, or social exclusion. For example, some people with autism fear that efforts to develop prenatal diagnostics for autism could erode progress toward their inclusion in society. The authors of the website "Learn from Autistics" discuss their fear that prenatal testing for autism will "likely lead to higher abortion rates and weaken whatever progress society has made towards autism acceptance" (2016). Reflecting on guidelines for the use of gene editing technologies such as CRISPR-Cas9, bioethicist Françoise Baylis notes that "The risks of increased discrimination (for example, racism, ableism, sexism) and stigmatization that accompany efforts to select for and against specific traits (particular characteristics and required qualities) are considerable" (Baylis 2017a). As an example, Baylis points out that members of the deaf community fear that "if they become fewer in number through overt efforts to ensure that they are not born, then they will experience increased discrimination. Manifestations of this discrimination might include renewed efforts to extinguish signed language and increased efforts at assimilation" (Baylis 2017a). There is strength in numbers, and the use of prenatal genomics may reduce the deaf population.

\subsubsection{Pathologization and Unintended Consequences}

In her book, The Gene Machine, Bonnie Rochman tells the story of Ryan Docherty (Rochman 2017). While in the prenatal stage, Ryan's mother had undergone an amniocentesis, and chromosomal microarray (CMA) analysis. The CMA revealed two variants of uncertain significance - one multi-gene duplication, and one multigene deletion. There is some evidence in the medical literature that an absence of one of the missing genes is associated with developmental and cognitive delays (Rochman 2017). These finding were significant enough for Ryan's parents that they were leaning towards terminating the pregnancy. However, a specialist in reproductive genetics reassured Ryan's parents that two variants were unlikely to have an effect. Ryan was born without any apparent cognitive disabilities (Rochman 2017).

This example shows that genomic technologies have the power to cast genetic differences as pathological. Without the influence of their specialist, Ryan's mother might well have opted for termination, thinking that the CMA had indicated that her 
fetus was genetically flawed. With only the bare genetic findings from the CMA, these concerns about the health of her potential child would be reasonable. Variants of uncertain significance, coupled with uncertain associations with disabilities, can be easily interpreted as genetic deficiencies, or as genetic risks.

Pathologization is not an abstract problem. It can have real effects, for instance, on the care that someone receives, on their well-being, or on their mortality. Consider the examples of trisomy 13 and trisomy 18. Unlike trisomy 21 (Down syndrome) these other trisomies have long been considered anomalies that are almost invariably fatal. However, in a recent editorial in JAMA, the neonatologist and ethicist John D. Lantos points out that over the past 30 years, survival rates for children born with trisomy 13 and 18 have been increasing (Lantos 2016). Referring to the latest population-based cohort study, " $12.9 \%$ of children with trisomy 13 and $9.8 \%$ with trisomy 18 survived to 10 years" (Lantos 2016, 397). Mortality is still high, but thirty years ago "no reports indicated that these infants survived until age 1 year" (Lantos 2016, 397). According to Lantos, the lack of survival 30 years ago can be attributed to the fact that pediatricians were taught that these trisomies were fatal, and that they tended to withhold life-sustaining treatment from such children. The infants who nonetheless survived were institutionalized. Lantos argues that "predictions of lethality become self-fulfilling prophecies" (Lantos 2016, 397). More children with these genetic conditions survive nowadays because they are given neonatal intensive care, and their parents bring them home to live with their families. These are the same factors that have contributed to the massive increase in life-expectancy of people with Down syndrome over the past several decades (Wright 2011).

Trisomy 13 and 18 are markedly different from Ryan Docherty's gene variants. However, a legitimate disability critique of the expansion of prenatal genomics could focus on the possibility that similar processes of pathologization could take place with regard to subchromosomal variants of unknown significance. We are moving into an era in which technologies such as prenatal whole-genome sequencing will give us massive amounts of data about our children in utero. There is no guarantee that we will make responsible or informed decisions, as individuals or as a society, about such data. It is troubling that a technology such as CMA could identify a genetic difference and contribute to the (mis)interpretation of this difference as a pathology. In the case of gene variants such as Ryan's, it is unlikely that the "selffulfilling prophecy" would be fatal. However the potentially negative consequences of pathologization cannot be clearly foreseen for all genetic differences.

\subsection{Expressing a Message: Claims and Examples}

The disability-based critiques I have articulated thus far focus on potential negative consequences for people with disabilities of the expansion of prenatal genomics. There is a further powerful critique of these technologies that focuses on the messages that their widespread use conveys to people with disabilities. This critique is often referred to as the "expressivist" objection. The use of these technologies is thought 
to express negative messages about disabilities because the technologies are often used to avoid the birth of people with disabilities.

The expressivist objection has various formulations. One version is that the use of these prenatal interventions "is an expression of disvalue for existing people" with the disabilities that are the target of testing (Hofmann 2017, p.1). Susan Wendell claims that the message sent by the widespread use of prenatal testing and selective abortion for disabilities is that "we do not want any more like you" (Wendell 1996, 153). Marsha Saxton argues that, "The message at the heart of widespread selective abortion on the basis of prenatal diagnosis is the greatest insult: some of us are 'too flawed' in our very DNA to exist; we are unworthy of being born" ([1998] 2010, 131).

Different formulations of the objection identify different individuals or groups as the purveyors of these messages. Some suggest that these harmful messages about disabilities are conveyed by the actions of individual prospective parents who choose prenatal testing or selective termination. Other formulations suggest that the messages arise from social trends (i.e. Saxton's reference to "widespread selective abortion"). The various formulations also differ slightly in the content of the message being sent. Some claim the message is about the desires of prospective parents (i.e. Wendell's interpretation: "we do not want any more like you") and others suggest that the message is about people with disabilities (i.e. Saxton's interpretation: "unworthy of being born"). The different formulations of the expressivist objection, however, share in common the claims that (1) the actions associated with testing for and selectively aborting fetuses with disabling conditions can send a message (or messages), or express a meaning, and (2) that the messages sent by these actions are negative or derogatory about people with the conditions for which people undergo testing.

In the following sections I draw upon Down syndrome as an example of a condition about which negative messages may be expressed through the social phenomenon of prenatal testing. I use this example because it is the most familiar to me, and because there has been a long history of prenatal testing and selective abortion for Down syndrome. Many of the arguments could apply equally well for other genetic conditions that correlate with cognitive disabilities, or physical disabilities, for which there are prenatal tests, or for which prenatal tests will likely be developed in the future. For example, Cri-du-chat syndrome and Wolf-Hirschhorn syndrome are conditions resulting from genetic microdeletions for which noninvasive screening tests have recently been developed (Dundorp et al. 2015). Autism is a condition with causes that are at least partly genetic, for which prenatal tests will likely be developed in the future. Though I often refer to Down syndrome, the expressivist argument I present could also apply to these conditions if prenatal testing results in high rates of selective abortion for these conditions.

Sex chromosome aneuploidies are an interesting further example. Noninvasive prenatal tests have newly become available for these conditions, such as Turner syndrome, Klinefelter syndrome (XXY) and triple-X syndrome. These aneuploidies have a variable phenotype that has been described as "generally mild" (Dundorp et al. 2015, 1443). For example, people with XYY syndrome (males with an extra Y chromosome) tend to have no physical differences compared to XY males other than a 
taller stature, and tend to have normal intelligence (Goobie and Prasad 2012). Some people with XYY syndrome have learning difficulties and behavioural problems, though it is difficult to assess the prevalence of these problems because cases of XYY syndrome prior to the availability of noninvasive screening typically went undetected (Goobie and Prasad 2012). Sex chromosome aneuploidies have a lower selective termination rate than Down syndrome (Boyd et al. 2011). If the selective termination rate for these conditions increases as a result of the routinization of NIPT, there would be grounds for advancing the expressivist argument, and for worrying about the likelihood that prenatal tests have pathologized these genetic differences.

\subsection{1 “Official” Messages}

One of the main problems to be confronted by those advancing the expressivist objection is the difficulty with attributing determinate messages to actions-such as the action of undergoing a selective termination. I will return to this issue below. However, the expressivist objection can also be directed at actual statements made by individuals, institutions, or governmental bodies. In these circumstances, there is less difficulty with raising the expressivist objection. In the UK for example, statements in the Human Fertilisation and Embryology Act (1990, amended 2008) and its supporting documentation make preimplantation genetic diagnosis (PGD) available only to determine whether a "serious genetic condition" is present in the embryo. ${ }^{1}$ The Human Fertilisation and Embryology Authority keeps a list of conditions that qualify under this legislative standard of being a "serious genetic condition" (Human Fertilisation and Embryology Authority 2018). Controversially, Down syndrome is one example of such a condition (Krahn 2011). In effect, the official government position of the UK is that Down syndrome is a serious genetic condition. Timothy Krahn notes that.

the HFEA licensing of PGD for Down's syndrome according to the standards established by
the HFE Act 1990 (as amended 2008), sends the message that this is a "serious condition"
that carries with it a significant risk of imposing significant suffering (or other compromising
features) for quality of life for the affected, prospective offspring and the families of these
affected offspring (Krahn 2011, 189).

Because of these messages, prospective parents would commonly be left with the impression that they should avoid bringing a child with this condition into the world.

Similarly, one of the original explanatory notes to the Bill that eventually became the Human Fertilisation and Embryology Act of 2008 stated that a goal of the Act was to prevent the selection of embryos that would result in a deaf child (Porter and Smith 2013). Through this explanatory note, the UK government expressed the view that prospective parents should avoid giving birth to a deaf child. The Act would eventually make it illegal to use IVF to do this. Christian Munthe similarly argues that publicly-funded and publicly-organized prenatal mass-screening programs that

\footnotetext{
${ }^{1}$ See: Human Fertilisation and Embryology Authority 2008.
} 
designate certain disabling conditions as the targets of screening send "an implied official message that certain types of people are undesirable" (Munthe 2015).

\subsubsection{Statements Made by Professionals}

The expressivist objection can also be directed unproblematically at statements made by individuals. Consider some examples uncovered by the historian of medicine Ilana Löwy. Löwy has traced out the history of prenatal diagnosis in the latter part of the twentieth century. She documents how Down syndrome emerged in the medical literature as a "public health problem" that could be addressed through screening programs and selective abortion (Löwy 2014, 290). Many professionals who advanced these initiatives during this period made stigmatizing statements about Down syndrome. In 1971, epidemiologists Zena Stein and Mervin Susser characterized people with Down syndrome as living in a "state of permanent dependence that imposes a severe burden on their families and on existing forms of social organization" (Stein and Susser 1971, 650). These authors make this claim in support of a plan to systematically screen for Down syndrome. In 1973, Stein and Susser, along with Andrea Guterman considered the practical difficulties of instituting a universal screening program for Down syndrome, including the difficulty of cost. They argued that, "The lifelong care of severely retarded persons is so burdensome in almost every human dimension that no preventive program is likely to overweight the burden" (Stein, Susser, and Guterman 1973, 308). Löwy also quotes an article from 1991 that states "the prevalence of Down syndrome has major resource implications" (Sheldon and Simpson 1991, 302). Similarly, an economic study of the incidence of congenital disabilities from 1994 discusses "birth defects' economic burden to society" (Waitzman, Romano, and Scheffler 1994, 188).

More recently, an economic analysis of enabling all pregnant women in the US to have access to NIPT mentions that "trisomy 21 is the most common fetal aneuploidy and has a high survival rate, leading to high medical costs" (Benn et al. 2015). According to the authors, "decreasing termination rates was associated with a reduction in NIPT value" (Benn et al. 2015), so the economic benefit to society of NIPT is contingent upon pregnant women choosing selective termination when given a prenatal diagnosis of trisomy 21 . The message being conveyed by such statements is that people with Down syndrome are a burden on their families, and on society. This explicit message, coupled with the push to screen for Down syndrome, clearly implies that such people should not be born.

Furthermore, some medical professionals continue to promote prenatal testing and selective abortion for Down syndrome in ways that express negative attitudes about people with this condition. Social science research reveals that some clinicians insist that pregnant women terminate pregnancies if given a Down syndrome diagnosis, and some perpetuate negative stereotypes about Down syndrome (for example Nelson Goff et al. 2013). These instances are direct and clear statements of disvalue about people with Down syndrome. 


\subsubsection{The Message Received by People with Disabilities}

Many people with disabilities and their advocates voice the sorts of concerns about the social phenomenon of prenatal testing that are articulated by expressivist objection. A report by the Nuffield Council on Bioethics on the implementation of NIPT in the UK quotes a person with Down syndrome as stating that the use of prenatal screening for his condition "makes me feel like I'm not wanted in society and no one loves us" (Nuffield Council on Bioethics 2017, 59). The Nuffield Council interviewed various stakeholders for their report. Other respondents with genetic conditions and advocates for people living with disabilities articulated similar objections (see Sect. 2.65-2.69).

The Canadian Down Syndrome Society's VATTA self-advocacy group has created a video, "What Prenatal Testing Means to Me" (Canadian Down Syndrome Society 2014). In the video, one of the self-advocates cites the high rates of selective termination for Down syndrome, and pointedly asks, "has anyone ever wondered how that makes us feel?". The question answers itself. Similarly, the "Don't Screen Us Out" advocacy group in the UK has clearly interpreted the widespread use of prenatal testing for Down syndrome as an effort to eliminate people with this condition through "screening" them out. The message they are receiving is that people with Down syndrome should not exist (Don't Screen Us Out 2017).

\subsection{The Social Phenomenon of Prenatal Testing}

Many different actors are involved in prenatal testing and selective abortion. Aside from the prospective parents who make testing and termination decisions, primary care physicians, obstetricians, midwives, and genetic counsellors take part in these activities. These professionals are also involved in developing guidelines about the use of prenatal genomic technologies, along with other actors such as epidemiologists, public health officials, ethicists, and managers of health care organizations. As we have seen, guidelines and policies are a particularly sensitive form of communication subject to the expressivist objection. In addition to these groups, scientists and industry executives are involved in developing and marketing new prenatal tests, some of which can currently detect conditions that were previously undetectable prenatally. Health insurance industry executives, health systems bureaucrats, and political decision-makers are involved in determining whether the new tests will be funded through private and public health insurance plans. The motives, goals, and social forces to which each of these actors are subject can be examined through the lens of the expressivist objection. One can ask, for instance, whether a corporate decision to create a product that makes it easier to test for Down syndrome conveys any negative messages about this condition, or whether a political decision to provide public funding for such a test conveys these messages.

The fact that there can be many targets of the expressivist objection beyond the individual choices of individual prospective parents suggests that we should examine 
prenatal testing and selective abortion as a social phenomenon that is larger than individual choices. What I am calling the "social phenomenon" of prenatal testing encompasses many events, decisions, actions, policies: pieces of information related to prenatal testing from which one can possibly take away an underlying social message about disability.

Within the network that is subject to the expressivist objection we must include the actions of prenatal test development companies who invest large sums of money in the creation and marketing of new prenatal tests, enticed by the promise of large profits. Through these extensive efforts to develop new and more user-friendly tests these companies act on the assumption that many people value being able to identify disabilities prenatally, and that the public will use their products. We must also include the decisions of professional physician groups who develop practice guidelines for new prenatal tests. These guidelines follow a typical logic in which a restricted group of pregnant women are first deemed eligible for testing because they are considered at greater "risk" (i.e. women over 35 years of age), and then as time passes eligibility is broadened to include all pregnant women (e.g. Summers et al. 2007). The social phenomenon of prenatal testing must include as well the high rates of selective termination for certain indications $-67 \%$ choose termination after being given a prenatal diagnosis of Down syndrome, according to one study, $90 \%$ according to another study (Natoli et al.2012; Mansfield et al. 1999). Another aspect of this social phenomenon is the typical routinization of prenatal testing in which women are offered prenatal tests, or these tests are administered, despite a lack of appropriate informed consent (Seavilleklein 2009; Thomas 2017). The attitude that such tests are "routine" is prevalent even though there is no prenatal treatment for the disabilities in question except termination of pregnancy, and even though the prospective parents who engage in prenatal testing in order to prepare for the possible birth of a child with a disability are a small minority. These facts suggest that clinicians who have made prenatal testing routine assume or even expect that pregnant women will terminate when they are given a prenatal diagnosis of a disability. My use of the concept of the "social phenomenon of prenatal testing" is meant to signify all of these events, decisions, policies, experiences, and actions.

\subsection{Meaning and Medicalization}

Since I am taking aim at a social phenomenon rather than any given individual actions, the challenge is to show that a multi-faceted group of events and choices has a more-or-less determinate meaning. I must show how a social phenomenon can mean something.

The underlying theory of meaning I will draw upon here is the Wittgenstinian theory presented by Jamie Lindemann Nelson in the article, "The Meaning of the Act: Reflections on the Expressive Force of Reproductive Decision Making and Policies" (Nelson 1998). According to Nelson, "the meaning of a symbol is a matter of how it is used, its role in a publicly shareable system of symbols" (Nelson 1998, 178). 
This view is one of the hallmarks of a Wittgenstinian theory of meaning. Meaning is determined by use in a language or system of symbols. Practices such as speech acts, gestures, or actions can convey meaning by participating in a game-like activity that is guided by rules. These ideas about the rules that regulate the meaning of a practice are captured by Wittgenstein's term "language-game" (Wittgenstein [1953] 1997). The meaning of an action is determined by the role it plays as set out by the rules of a language-game. This view contrasts with theories of meaning that locate the meaning of linguistic acts in the beliefs, thoughts, or intentions of speakers. As Nelson explains, meaning can be distinguished from the intentions of the speaker, or his or her beliefs: "practices might have expressive content in a way that is not solely a function of our beliefs" (Nelson 1998, 178). Nelson makes this point in order to counter a potential argument against the expressivist objection. According to this anti-expressivist position, a prospective parent might argue that a choice to selectively terminate does not express a negative message about disabilities because no such message was intended. Such a person might claim that she chose selective termination, for instance, because she was concerned about the economic impact on her family of raising a child with a disability. According to the Wittgensteinian theory of meaning, selective termination might nonetheless convey a negative message about disabilities regardless of what the prospective parent intended. The choice to selectively terminate might play a role in a language game whose outcome is a negative message about disabilities.

A further aspect of a Wittgensteinian theory of meaning is that the systems of rules that determine meaning (language-games) should not be seen as strict and unchanging. Language-games are conventional. The rules of language-games themselves also arise out of our practices, just as the practices that convey meaning based on these rules are part of our conventional activity. These conventional activities in which language games are embedded are what Wittgenstein calls a "form of life" (Wittgenstein [1953] 1997).

To illustrate this theory of meaning, consider an example. Nelson contrasts prenatal testing and termination decisions with the action of raising the confederate flag over the South Carolina State House. In her estimation, flying the flag has an unambiguous racist meaning, regardless of the intentions or beliefs of those who are responsible: "One simply could not say that flying the battle flag over the State House means whatever 'we' want it to mean" (Nelson 1998, 178). Instead of being determined by the intentions of those who raise the flag, the meaning of flying the flag is rather set in place by the historically determined system of symbols in which the confederate flag operates as a representation and endorsement of the practice of slavery. Within the historically determinate form of life of the old South, the flag represents support for the states that fought to preserve slavery. The "languagegame" of raising flags and using flags to represent states and armies, determines this meaning. The person who raises the flag on a given day might not have intended to convey a racist message. Nonetheless, the act's participation in this system of symbols embedded in this particular form of life is responsible for the message it conveys. 
Though Nelson goes along with the expressivist argument this far by outlining a theory of meaning by which an action can convey a message, she ultimately does not endorse the expressivist position. Nelson argues that the practice of prenatal screening for disabilities, and of selective termination "do not take place against a settled practice of seeing them as expressing what a community is and with what it identifies" (Nelson 1998, 178). According to Nelson, the actions associated with prenatal testing and selective abortion do not take place within a system of symbols that is semantically stable enough to avoid ambiguity. On this view, there is no "language-game" within which the practice of prenatal testing operates that gives it an anti-disability meaning. Because ambiguity is not avoided, Nelson argues, prenatal testing and selective abortion cannot legitimately be seen as expressing any determinate messages.

To contest Nelson's argument, I believe that there is a "settled practice" or set of "language-games" that provides a semantic framework within which the social phenomenon of prenatal testing can be legitimately interpreted as sending negative messages about people with disabilities. This settled practice is medicalization: specifically the medicalization of pregnancy, and the medicalization of disability. Medicalization is the practice of viewing these conditions (pregnancy, disability) through the lens of biomedicine. The medicalization of disability, for instance, takes a category of human difference, and makes the category a subject of medicine. A hallmark of medicalization is the transformation of features of normal human life into pathological states, when these features might otherwise be understood merely as instances of normal human variation, or go unrecognized altogether. Medical discourse and practices thus regard disabilities as problems to which diagnostics, and treatments or interventions should be applied (Conrad 2007). The medical profession has the epistemic authority to dictate what constitutes a normal human body, mind, or genetic code, and what constitutes a departure from normality. According to the medicalized depiction, the problems associated with disabilities inhere in the body of the person himself or herself who has the disability. The cause is within. The solution to these problems is to fix or treat the body. I will argue that just as raising the confederate flag cannot avoid sending a racist message, disability is caught up in a system of screening, diagnostics, technological intervention, and professional expertise that cannot avoid sending the message that the birth of people with disabilities should be avoided.

The medicalized story is not the only way of understanding disability. The medicalization of disability is only one contender among others offering a public understanding of what disability is. For instance, the "social model" of disability is another view (Krahn 2011; Saxton [1998] 2010). According to the social model, disabilities do not inhere in, and are not caused by, features of the person himself or herself, but are instead caused by one's social arrangements and social environment. To use a well-worn example, someone who uses a wheelchair will be disabled by a lack of accessibility features in the built environment, such as ramps. When these disabling features of the social environment and social organization are addressed, disability no longer exists. Stigma and bias directed at people with disabilities are further disabling features of the social environment. According to Marsha Saxton, disability 
results from "discriminatory attitudes and thoughtless behaviors, and the ensuing ostracism and lack of accommodation" (Saxton [1998] 2010, 122) rather than from the physical or cognitive characteristics of individuals. Those who endorse the social model would improve the lives of people with disabilities by addressing these social causes of disability, rather than fixing their bodies, minds, or genetic codes. One implication of the social model is that disability is not viewed as pathological.

Though the social model is a contender for the public understanding of disability, the medicalized view is dominant. The social model is a minority perspective that has only partial influence on public understanding. The high rates of selective termination for disabilities like Down syndrome are suggestive of the dominance of the medicalized view of this condition. These high rates are more consistent with viewing Down syndrome as a genetic disorder, rather than with viewing society as disordered in its inability to accommodate the needs of people with genetic differences (Lippman 1991). Furthermore, the medicalized view of disability is dominant because powerful actors advance this view. Doctors are the traditional agents of medicalization, and these professionals are influential. Their influence has been joined by the biotechnology industry, large pharmaceutical corporations, and well-funded genetics researchers (Conrad 2007). The industrial actors behind recent advances in prenatal genomics are highly profitable and are able to project the messages needed to promote their products into the medical profession and directly to consumers (Munthe 2015). These messages require that genetic differences associated with disability are seen as pathological so that there is an urgency to their identification in utero. The agents who advance the social model of disability, in contrast, are significantly less influential and command comparatively meagre resources. These agents consist in disability activists, academics, and grass-roots advocacy organizations.

\subsection{The Meaning of the Social Phenomenon of Prenatal Testing}

In affluent societies, pregnancy is a thoroughly medicalized condition. Prenatal care typically involves technological monitoring virtually from the beginning, including such processes as the confirmation of pregnancy through testing, both at home, or by a health care professional, and the common use of ultrasound to confirm fetal age or the date of conception. Ongoing care throughout pregnancy involves various routine blood tests, weight monitoring, and regular expert surveillance through check-ups. In different ways, pregnant women are also offered advice on diet and lifestyle that has been developed through biomedical expertise. When women give birth in hospitals, babies enter the world in highly technologized environments with associated pharmacological, physical, or surgical means for facilitating their delivery. Even with less medicalized versions of this arc of care, such as midwifery care, the technological biomedical interventions are usually available and waiting in the wings in case anything does not go to plan. 
Pregnancy is judged against a standard of normalcy developed by biomedicine (Sherwin 2001). Deviations from the "normal" are handled by further medical interventions or by increased technological surveillance. Within the medicalized context of pregnancy, the dominant understanding of disability is also highly medicalized. Consider, for instance, the definition of Down syndrome provided by the Mayo Clinic:

\footnotetext{
Down syndrome is a genetic disorder caused when abnormal cell division results in an extra full or partial copy of chromosome 21 . This extra genetic material causes the developmental changes and physical features of Down syndrome.

Down syndrome varies in severity among individuals, causing lifelong intellectual disability and developmental delays. It's the most common genetic chromosomal disorder and cause of learning disabilities in children. It also commonly causes other medical abnormalities, including heart and gastrointestinal disorders (Mayo Clinic 2018).
}

This definition is meant to be fact-based, clinical, and inoffensive. However, it presents a particular understanding in which people with Down syndrome have all sorts of problems (intellectual and learning disabilities, developmental delays, and medical abnormalities) and these problems are caused by a genetic feature that inheres within the person himself or herself who has Down syndrome. The problem can be found within the person, rather than outside of the person in the social circumstances that make uncommon learning and developmental needs difficult to accommodate (Kaposy 2018).

Against the background of a medicalized understanding of pregnancy and of disability, a pregnant woman who is found to be carrying a fetus with trisomy 21 is a departure from normalcy, and is a candidate for intervention or increased medical monitoring. As Susan Sherwin notes, within the medicalized worldview all pregnancies are seen as potentially high risk problematic pregnancies. Maternity hospitals, for instance, are organized in a way that is poised to respond to unforeseen crisis for any delivery (Sherwin 2001). There is thus a strong biomedical need to identify, during the prenatal stage in as many pregnancies as possible, whether any "problems" exist before they become crises. The expansion and perfection of prenatal genetic screening and diagnostics are a part of this effort to anticipate, identify, intervene, and counter any problems that occur in pregnancy. The very fact that such effort is taken to test for disabilities in pregnancy indicates to the audience of those who would undergo testing that disabilities are negative characteristics that should be eliminated (Thomas 2017; Lippman 1991).

Within the logic of medicalization, medical testing is used to identify diseases, disorders, disabilities, and the like - departures from normal health, as defined by the medical profession. Genetic variations in pregnancy are defined as problems, and problems must be monitored. The purpose of identifying and monitoring problems is to administer a medical or technical solution. Prenatal testing can help identify fetuses that need prenatal interventions like transfusions, or postnatal intensive care access. But in most cases, in the prenatal period, the only solution currently available for avoiding the identified "problem" of disability is to terminate the pregnancy and avoid giving birth. 


\subsubsection{Examples of Medicalization in Action}

The processes of medicalization encountered at the level of the prenatal clinic reinforce the view that disabilities are something to be avoided, and thus that disabled children ought not to be born. Gareth Thomas's in-depth study of Down syndrome screening at clinics in the UK highlights several features of the process of medicalization that contribute to this message (Thomas 2017). Thomas's work shows how practices in the delivery of prenatal care convey negative messages about disability. Though these examples would likely not occur in every clinic, they illustrate how medicalization can be actualized in the clinic in a way that favours a certain view of disabilities. According to Thomas, "Down's syndrome is imbued with negativity ... as something which can and should be detected and, if a diagnosis is established, as something which constitutes a reason for terminating a pregnancy" (Thomas 2017, 177).

For instance, midwives in the clinics Thomas studied frequently referred to Down syndrome as a "risk", a "problem", or as an "abnormality" (Thomas 2017, 131). Language like this conveys the direct impression that Down syndrome is something that prospective parents ought to avoid. Thomas also documents several instances in which sonographers informed prospective parents that if they received a positive result on a Down syndrome screening test, amniocentesis would be "advised" (Thomas 2017, 79). The message here is that according to professional medical opinion, Down syndrome is something important to diagnose, or a condition with a dire impact. The language used to describe Down syndrome or the screening process carries powerful messages about disabilities.

Thomas's study shows furthermore that Down syndrome is pathologized in offhand ways by the screening process. In the clinics Thomas studied, little time was allocated to pre-screening counselling, leading to the impression that screening for Down syndrome was a routine procedure in which pregnant women would normally and obviously want to participate (Thomas 2017). Furthermore, during the limited counselling time provided, there was a lack of discussion about Down syndrome itself, and the screening test for this condition was offered in conjunction with tests for "rubella, HIV, syphilis, rhesus disease, sickle-cell disease, thalassemia, hepatitis B/C" (Thomas 2017, 132). The combination of the lack of discussion about Down syndrome, and the inclusion of Down syndrome among these diseases, surely conveys the message that it is obvious that one should screen for Down syndrome. In such a context, a patient can easily assume that there is no need to discuss Down syndrome because, like syphilis, it is something that a parent would want to avoid.

The organization of Down syndrome screening in such clinics was set up to lead to termination should the fetus be diagnosed with Down syndrome. For instance, in one clinic, pregnant women who received a positive screening result for Down syndrome were pre-booked for an amniocentesis (and were told about this pre-booked appointment) even before the pregnant women had established for themselves that they wanted this procedure, and before they had given their informed consent (Thomas $2017,117)$. The official reason for this practice was the administrative necessity of 
managing appointment bookings within the short window of time between screening, diagnostic testing, and the availability of termination. But even so, these procedures presuppose that there is an urgency to identify fetuses with Down syndrome so that a termination can be scheduled in a short period of time.

A further example of this feature of medicalization is the practice of "reflex testing" with NIPT as a secondary screening test. Reflex testing is the practice of taking two samples of blood from pregnant women so that if the first sample provides a positive result for a trisomy like Down syndrome on a less-accurate screening test, the second sample can automatically be used for more accurate NIPT (Ravitsky 2017; Wald et al. 2017). Some clinicians have recently begun the practice (Wald et al. 2017). In such instances it may be unclear whether the women have consented to the secondary screening test. The assumption behind such testing is that pregnant women would obviously want to know whether their fetuses have a disabling condition so that they can take action based on this information. This assumption makes sense only if it is first assumed that disabilities are something that prospective parents ought to avoid.

\subsubsection{The Logic of Medicalization}

Returning to Nelson's analogy, the Confederate flag cannot mean anything we want it to mean. Meaning is held in place by a history of practices, by the language-games in which an act plays a role. Similarly, the medicalization of pregnancy and the medicalization of disability provide a stable set of meanings to the social phenomenon of prenatal testing. The set of practices associated with medicalization hold a particular meaning in place. These practices include the procedural steps that begin with surveillance in pregnancy, and screening tests, which lead to diagnostic testing, and ultimately to treatment, which in the case of prenatal testing is the termination of pregnancy. These work processes of screening, diagnosis, and treatment follow a commonplace logic of medical care. According to this logic, the genetic differences identified as disabilities are pathological—something to be avoided in pregnancy. The message is that people with such differences should not be born. Medicalization inhibits us from making these processes mean whatever we want them to mean.

The vast sums of money devoted to perfecting the prenatal identification of genetic differences make sense within this logic of medicalization in which disabilities are pathologies to be avoided. Test development companies obsessively market their products as providing early detection (e.g. LifeLabs Genetics 2018). The main purpose of early detection is to enable fetal diagnosis early enough in pregnancy for termination to be available, since many jurisdictions limit access to abortion past a point sometime in the second trimester of pregnancy.

The expansion of prenatal testing through professional guidelines that extend testing programs so that they include all pregnant women makes sense within this pathologized depiction of disabilities. According to the medicalized understanding 
of disability, it is necessary to avoid the birth of people with these differences whenever possible, so prenatal testing must be made available to everyone. Selective termination rates are high because disabilities are understood as pathological.

The clinical routinization of prenatal testing likewise makes sense within this medicalized framework. Within this way of thinking it is simply obvious that prospective parents would want to avoid the birth of children with genetic disabilities, so there is no great impetus to gain proper informed consent. Since a medicalized understanding of disability is dominant in our culture, when people with disabilities witness these aspects of the social phenomenon of prenatal testing, it is legitimate for them to interpret this phenomenon as expressing the message that people like them should not have been born.

\subsection{Autonomy as an Outcome Rather than Termination}

Some will dispute this account and claim that there is an alternate meaning that can be attributed to the medical processes of prenatal testing. According to this alternate interpretation, the endpoint of the screening and diagnostic process is not the termination of pregnancy, but the autonomous choice of the pregnant woman to either terminate or to continue the pregnancy. The autonomous choice to refuse prenatal screening or diagnostic testing is also available to the pregnant woman. Prenatal testing procedures thus support autonomous choice, one might claim, and medicine is agnostic about the social worth of people with disabilities.

But the very fact that there is prenatal testing at all for disabilities, and millions of dollars poured into the development of better tests, suggest something other than agnosticism and support for autonomous choice. Clearly disability is not perceived as a mere difference by the actors who advance these interests. The social phenomenon of prenatal testing has not developed over decades as a way of identifying mere differences in the fetus. Disabilities are clearly perceived as something pathological. The belief that prenatal testing is meant to support autonomous choice is consistent with a belief that a child with a disability is full of problems about which prospective parents should at least be warned. In contrast, the medical profession finds it acceptable to leave mere differences up to chance. For instance, when there is a technological advance, such as prenatal whole-genome sequencing, that would enable prospective parents to pick and choose babies according to traits such as eye-colour or hair-colour, choruses of opposition rise up against "designer babies". Enabling prenatal choices about disabilities engenders very little opposition. There is comparatively more ethical disquiet about the prospective development of prenatal genetic tests for traits perceived to be "neutral".

The depiction of prenatal testing as supporting autonomous choice, rather than leading to selective termination, actually fixes the same messages about disability into place. The all-important mandate to support autonomous choice in reproduction can be read as a duty to warn prospective parents about the consequences of choosing to continue their pregnancies. Choices that are perceived to be unorthodox or potentially 
harmful invite increased scrutiny. Prenatal testing is a form of increased scrutiny over choices in pregnancy.

As an analogy, we respect the autonomy of people who choose to go back-country skiing, who scuba dive with sharks, go skydiving, or who stay in town during a hurricane. But we make sure that their choices are informed. We convey the message that, "this could be really bad for you, are you really sure you want to do this?" These analogies show that the process of scrutiny and warning is consistent with respecting autonomy. Orthodox choices, in contrast, invite little or no scrutiny. The routinization of prenatal testing, and the expansion of categories of pregnant women eligible for new forms of prenatal testing, suggest that in the medicalized worldview, pregnant women ought to know whether they are carrying a fetus with a disability. The orthodox choice is to undergo prenatal testing. Even though prenatal testing supports autonomous choice, the underlying logic of medicalization still conveys the unavoidable message that people with disabilities should not be born. To swim against the current of orthodoxy and instead choose to bring a child with a disability into the world requires being first met with warnings and scrutiny about the supposed harm that this choice could bring.

\subsection{Conclusion}

I have argued that the expansion of prenatal genomics, as embodied by the social phenomenon of prenatal testing, sends the message that people with disabilities ought not to have been born. I began by outlining a few disability-based objections to the expansion of prenatal genomics that focus on the potential consequences for people with disabilities of this expansion. From there, I developed an argument in support of the expressivist position. According to the argument, the social phenomenon of prenatal testing sends this negative message about people with disabilities.

The social phenomenon of prenatal testing, as I have defined it, includes the actions of a variety of agents and organizations, such as prospective parents, clinicians, prenatal test development companies, health system decision-makers, and professionals who create clinical practice guidelines. To address the question of how the actions of such a disparate set of actors could convey a univocal message about disability, I pointed out that all of these actions are unified by the overarching medicalization of pregnancy, and the medicalization of disability.

The logic of medicalization provides a Wittgensteinian "language-game" within which all of the actions that contribute to the social phenomenon can be seen as expressing a common message. According to Wittgenstein's theory of meaning, the rules of language-games are not abstract and immutable universal truths. These rules arise out of our practices. Our language games derive from what Wittgenstein calls our "form of life". We can judge the meaning conveyed by a practice such as prenatal testing by attending to the background form of life within which the practice is historically entrenched. As we have seen, the social phenomenon of prenatal testing participates in the logic of medicalized screening and diagnostic tools designed to 
eliminate disease. NIPT is a screening tool. Such tools are used by the medical profession to eliminate pathology. In this case, the "pathology" in question is genetic difference. Within the context of this dominant set of medicalized practices, it is straightforward to believe that the social phenomenon of prenatal testing sends the message that people with these genetic differences should not be born.

People with disabilities are therefore justified when they believe that the expansion of prenatal genomics conveys negative messages about them and their lives. The disruption of these negative messages would require the rejection of the medicalization of disability, and of pregnancy, by the wider culture, and would require questioning the social value of the technological tools that enable us to reduce the number of people with genetically-based disabilities in our communities.

\section{References}

Aymé, S. 2016. If rare diseases are so rare, why do they matter? On Biology. https://blogs.biomed central.com/on-biology/2016/02/29/if-rare-diseases-are-so-rare-why-do-they-matter/. Accessed 22 June 2018.

Baylis, F. 2017a. Gene editing: Where should we draw the line? Impact Ethics. https://impacteth ics.ca/2017/10/25/gene-editing-where-should-we-draw-the-line/. Accessed 26 Feb 2018.

Baylis, F. 2017b. Genome editing of human embryos broadens ethics discussions. The Conversation. http://theconversation.com/genome-editing-of-human-embryos-broadens-ethicsdiscussions-84888. Accessed 15 Feb 2018.

Benn, P., K.J. Curnow, S. Chapman, S.N. Michalopoulos, J. Hornberger, and M. Rabinowitz. 2015. An economic analysis of cell-free DNA non-invasive prenatal testing in the US general pregnancy population. PLoS One 10: $\mathrm{e} 0132313$.

Boyd, P.A., M. Loane, E. Garne, et al. 2011. Sex chromosome trisomies in Europe: Prevalence, prenatal detection and outcome of pregnancy. European Journal of Human Genetics 19: 231-234.

Canadian Down Syndrome Society. 2014. What prenatal testing means to me. youtu.be/VQp8OJN5Rjk. Accessed 28 Feb 2018.

Conrad, P. 2007. The medicalization of society: On the transformation of human conditions into treatable disorders. Baltimore: Johns Hopkins University Press.

Don't Screen Us Out. 2017. Our concerns. http://dontscreenusout.org/. Accessed 26 Feb 2018.

Dondorp, W., G. de Wert, Y. Bombard, et al. 2015. Non-invasive prenatal testing for aneuploidy and beyond: Challenges of responsible innovation in prenatal screening. European Journal of Human Genetics 23: 1438-1450.

Goobie, S., and C. Prasad. 2012. XYY syndrome. eLS: Citable Reviews in the Life Sciences. https:// doi.org/10.1002/9780470015902.a0005157.pub2. Accessed 30 June 2018.

Gyngell, C., and T. Douglas. 2016. Selecting against disability. The liberal eugenic challenge and the argument from cognitive diversity. Journal of Applied Philosophy 33(4).

Hofmann, B. 2017. You are inferior! Revisiting the expressivist argument. Bioethics, 31 (7): 505514.

Human Fertilisation and Embryology Authority. 2018. PGD conditions. https://www.hfea.gov.uk/ pgd-conditions/. Accessed 28 Feb 2018.

Human Fertilisation and Embryology Authority. 2008. Human Fertilization and Embryology Act 2008, Code of Practice. https://www.legislation.gov.uk/ukpga/2008/22/section/23. Accessed Nov 72021. 
International Summit on Human Gene Editing. 2015. On human gene editing: International summit statement. https://www.nationalacademies.org/news/2015/12/on-human-gene-editinginternational-summit-statement. Accessed 15 Feb 2018.

Grant, K. 2018. The birth of a revolution in prenatal screening. The Globe and Mail, 10 Jan 2018. https://www.theglobeandmail.com/life/parenting/new-prenatal-tests-for-parents-getsmixed-feelings/article37570374/. Accessed 26 Feb 2018.

Kaposy, C. 2013. A disability critique of the new prenatal test for Down syndrome. Kennedy Institute of Ethics Journal 23(4): 299-324.

Kaposy, C. 2018. Choosing Down syndrome: Ethics and new prenatal testing technologies. Cambridge, MA: MIT Press.

Krahn, T.M. 2011. Regulating preimplantation genetic diagnosis: The case of Down's syndrome.Medical Law Review 19: 157-191.

Lantos, J.D. 2016. Trisomy 13 and 18 - treatment decisions in a stable gray zone. JAMA 316(4): 396-398.

Learn from Autistics. 2016. Prenatal screening for autism. https://learnfromautistics.com/prenatalscreening-for-autism/. Accessed 27 June 2018

LifeLabs Genetics. 2018. Learn important health information about your baby, earlier. https://www. lifelabsgenetics.com/product/non-invasive-prenatal-testing/. Accessed 22 June 2018

Lippman, A. 1991. Prenatal genetic testing and screening: Constructing needs and reinforcing inequities. American Journal of Law and Medicine 17: 15-50.

Löwy, I. 2014. Prenatal diagnosis: The irresistible rise of the "visible" fetus. Studies in the History and Philosophy of the Biological and Biomedical Sciences 47: 290-299.

Mansfield, C., S. Hopfer, and T.M. Marteau. 1999. Termination rates after prenatal diagnosis of Down syndrome, spina bifida, anencephaly, and Turner and Klinefelter syndromes: A systematic literature review. Prenatal Diagnosis 19: 808-813

Mayo Clinic. 2018. Down syndrome: Symptoms and causes. https://www.mayoclinic.org/diseasesconditions/down-syndrome/symptoms-causes/syc-20355977. Accessed 28 Feb 2018

Munthe, C. 2015. A new ethical landscape of prenatal testing: Individualizing choice to serve autonomy and promote public health: A radical proposal. Bioethics 29(1): 36-45.

Natoli, J.L., D.L. Ackerman, S. McDermott, and J.G. Edwards. 2012. Prenatal diagnosis of Down syndrome: A systematic review of termination Rates (1995-2011). Prenatal Diagnosis 32: 142 153

Nelson Goff, B.S., N. Springer, L.C. Foote, C. Frantz, M. Peak, and C. Tracy, et al. 2013. Receiving the initial Down syndrome diagnosis: A comparison of prenatal and postnatal parent group experiences. Intellectual and Developmental Disabilities 51(6): 446-57.

Nelson, J.L. 1998. The meaning of the act: Reflections on the expressive force of reproductive decision making and policies. Kennedy Institute of Ethics Journal 8(2): 165-180

Nuffield Council on Bioethics. 2017. Non-invasive prenatal testing: Ethical issues. https://www. gov.uk/government/news/safer-screening-test-for-pregnant-women. Accessed 15 Feb 2018.

Porter, G., and M.K. Smith. 2013. Preventing the selection of "deaf embryos" under the Human Fertilisation and Embryology Act 2008: Problematizing disability? New Genetics and Society 32(2): 171-189.

Ravitsky, V. 2017. Choice not "reflex": Routine prenatal screening. Impact Ethics. https://impact ethics.ca/2017/12/01/choice-not-reflex-routine-prenatal-screening/. Accessed 28 Feb 2018.

Rochman, B. 2017. The gene machine: How genetic technologies are changing the way we have kids - and the kids we have. New York: Scientific American / Farrar Strauss and Giroux.

Saxton, M. 2010. Disability rights and selective abortion. In The Disability Studies Reader, ed. Lennard J. Davis, 120-132. New York: Routledge

Seavilleklein, V. 2009. Challenging the rhetoric of choice in prenatal screening. Bioethics 23(1): $68-77$.

Sequenom. 2017. Screen for more than Down syndrome. https://www.sequenom.com/uploads/col lateral/MaterniT-GENOME-patient-brochure_Rep-1038.pdf. Accessed 15 Feb 2018. 
Sheldon, T., and J. Simpson. 1991. Appraisal of a new scheme for prenatal screening for Down's syndrome. British Medical Journal 302: 1133-1136.

Sherwin, S. 2001. Normalizing reproductive technologies and implications for autonomy. In Globalizing feminist bioethics: Crosscultural perspectives, ed. R. Tong, 96-113. Boulder, CO: Westview Press.

Stein, Z., and M. Susser. 1971. The preventability of Down's syndrome. HSMHA Health Reports 86: 650-658.

Stein, Z., M. Susser, and A. Guterman. 1973. Screening programme for prevention of Down's Syndrome. The Lancet 301: 305-310.

Summers, A.M., S. Langlois, P. Wyatt, and R.D. Wilson, et al. 2007. Prenatal screening for fetal aneuploidy. Journal of Obstetrics and Gynaecology Canada 29(2): 146-161.

Thomas, G. 2017. Down's syndrome screening and reproductive politics: Care, choice, and disability in the prenatal clinic. New York: Routledge.

Wald, N.J., W.J. Huttly, J.P. Bestwick, et al. 2017. Prenatal reflex DNA screening for trisomies 18, and 13. Genetics in Medicine, 20(8): 825-830.

Waitzman, N.J., P.S. Romano, and R.M. Scheffler. 1994. Estimates of the economic costs of birth defects. Inquiry 31(2): 188-205

Wendell, S. 1996. The rejected body. New York: Routledge.

Wittgenstein, L. [1953] 1997. Philosophical investigations. G.E.M. Anscombe, trans. Cambridge, MA: Blackwell

Wright, D. 2011. Downs: The history of a disability. New York: Oxford University Press.

Open Access This chapter is licensed under the terms of the Creative Commons Attribution 4.0 International License (http://creativecommons.org/licenses/by/4.0/), which permits use, sharing, adaptation, distribution and reproduction in any medium or format, as long as you give appropriate credit to the original author(s) and the source, provide a link to the Creative Commons licence and indicate if changes were made.

The images or other third party material in this chapter are included in the chapter's Creative Commons licence, unless indicated otherwise in a credit line to the material. If material is not included in the chapter's Creative Commons licence and your intended use is not permitted by statutory regulation or exceeds the permitted use, you will need to obtain permission directly from the copyright holder.

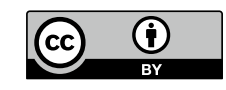

